\title{
O Retrato Sociológico como método investigativo em pesquisas brasileiras nas áreas de Educação e de Ensino: uma revisão de teses publicadas entre 2011 e 2020
}

\section{Sociological Portraits as an investigative method in Brazilian research in the fields of Education and Teaching: a review of dissertations published between 2011 and 2020}

Guilherme Dias ${ }^{1}$

Ricardo Gauche ${ }^{2}$

\author{
'Secretaria de Estado de Educação do Distrito Federal, Brasília, DF, Brasil. \\ Autor Correspondente: guilherme.dias@se.df.gov.br \\ ${ }^{2}$ Universidade de Brasília (UnB), Instituto de Química, Brasília, DF, Brasil.
}

Resumo: O Retrato Sociológico é caracterizado como um dispositivo teóricometodológico biográfico que se vale de narrativas orais e outras manifestações de um ator social para a reconstrução do patrimônio de disposições desse ator, com o intuito de compreender como o social é por ele incorporado. Entre 2011 e 2020, algumas pesquisas brasileiras utilizaram essa metodologia para compreender a influência das disposições nas trajetórias escolares, nas práticas de leitura de indivíduos, do bilinguismo e na construção das identidades profissionais docentes. Para melhor compreender como se deu o uso desse instrumento metodológico, este artigo apresenta uma revisão de teses publicadas no Brasil naquele período. O levantamento nos permite concluir que o uso do Retrato Sociológico, como parte do método de pesquisa, contribui com um novo olhar sobre a maneira como o social é apreendido pelo indivíduo, seja ele estudante ou professor.

Palavras-chave: Metodologia da pesquisa; Educação e ensino; Teses; Pesquisa bibliográfica.

Abstract: The Sociological Portrait is characterized as a biographical theoreticalmethodological device, in which the oral narrative and other manifestations are used to reconstruct the legacy of an individual's dispositions, to understand how him/her incorporates the social domain. Between 2011 and 2020, some Brazilian studies used this methodology to understand the influence of dispositions on school trajectories, on the reading practices of individuals, of bilingualism and on the construction of professional teaching identities. To better understand how this methodological instrument was used, this article presents a review of dissertations published in Brazil during that period. The review allows us to conclude that the use of the Sociological Portrait, as part of research methods, contributes to a new look at the way the social domain is apprehended by the individual, whether student or teacher.

Keywords: Research methodology; Education and teaching; Dissertations; Bibliographic research. 


\section{Introdução}

O Retrato Sociológico é caracterizado como um instrumento teóricometodológico de caráter biográfico em que relatos orais e outras fontes de manifestações são utilizados para reconstruir o patrimônio de disposições de um indivíduo. Foi proposto por Bernard Lahire como um dispositivo capaz de renovar o método biográfico enquanto metodologia de pesquisas nas Ciências Sociais (LAHIRE, 2004).

Assim como outras metodologias biográficas, o Retrato Sociológico foi apropriado e é utilizado atrelado a problemas de pesquisa em investigações em outras áreas de conhecimento, como nas de Educação e de Ensino, por exemplo.

Trajetórias de escolarização, evasão no Ensino Superior, afiliação institucional, gosto pela leitura e reflexões sobre práticas docentes estão entre os objetos de estudo analisados sob a ótica da teoria disposicionalista nas pesquisas brasileiras publicadas entre 2011 e 2020, que se valeram do Retrato Sociológico como dispositivo teóricometodológico de investigação e que serão revisadas no presente artigo. Essa diversidade de temáticas pode ser considerada indício de um potencial de vasto uso dessa ferramenta investigativa em pesquisas nessas áreas.

Lima Júnior e Massi (2015, p. 571, grifo do autor) compartilham dessa percepção, em pesquisas em Ensino de Ciências, quando afirmam que o Retrato Sociológico permite um olhar renovado sobre velhas questões da área, "[...] na medida em que inscreve $a$ experiência científica e educacional de um ator individual" no conjunto de sua trajetória social, visto que as experiências de um ator nessa área estão diretamente ligadas às suas experiências de socialização em contextos diversos, como por exemplo, no familiar e no da prática religiosa.

Reforçando a ideia de potencialidade dessa metodologia, Massi (2018, p. 395) entende ser possível utilizar o Retrato Sociológico em investigações relacionadas à formação de professores, "[...] procurando responder quais [disposições] seriam marcantes e articuladas ao trabalho docente, como elas foram formadas, em que momento e como são alteradas contextualmente (por exemplo, através de um curso de formação continuada)".

Cientes desse potencial, buscamos compreender melhor como se deu o uso de Retratos Sociológicos como dispositivos teórico-metodológicos em investigações já realizadas e, assim, apresentamos, neste artigo, uma revisão de teses publicadas que fizeram uso desse método, entre os anos de 2011 e 2020, nas Áreas de Educação e de Ensino. Utilizamos como fonte de dados para essa revisão, o banco do Catálogo de Teses e Dissertações da Coordenação de Aperfeiçoamento de Pessoal de Nível Superior (CAPES).

Direcionamos nosso olhar em busca de aproximações e diferenças nos objetivos desses estudos, nas metodologias utilizadas para a construção e para a análise dos dados e refletimos sobre as contribuições advindas do uso dos Retratos Sociológicos como instrumento teórico-metodológico para as conclusões presentes nas teses revisadas. 


\section{O que é o Retrato Sociológico de Bernard Lahire?}

Apresentamos, a seguir, uma breve descrição do dispositivo teórico-metodológico chamado Retrato Sociológico e do contexto em que se deu a sua elaboração, com o intuito de estabelecermos comparações consoantes com as metodologias utilizadas nas investigações revisadas neste artigo.

Nas duas décadas anteriores à proposição do Retrato Sociológico por Lahire, houve uma eclosão de pesquisas (PINEAU, 2006) que utilizavam o método biográfico como instrumento de investigação nas Ciências Sociais, mas esse fato não se deu desacompanhado de críticas e objeções.

No artigo denominado A ilusão biográfica, publicado em 1998, Pierre Bourdieu teceu duras críticas ao uso do método biográfico, começando pela provocante afirmação de que as histórias de vida entraram como contrabando no meio acadêmico (BOURDIEU, 1998). Para além da provocação, a crítica era direcionada à aceitação, por parte de investigadores que utilizavam a metodologia biográfica, da existência de uma sequência cronológica e lógica nos acontecimentos da vida de um sujeito de pesquisa. Bourdieu entendia não ser possível existir uma linearidade progressiva e causal nos eventos vivenciados e posteriormente narrados pelas pessoas. Essa linearidade seria construída pelo narrador ou pelo pesquisador subsequentemente, considerando a necessidade de dar sentido às ações dos investigados (MONTAGNER, 2007). Para Bourdieu (1998, p. 188), "[...] o relato de vida tende a aproximar-se do modelo oficial da apresentação de si", e assim, seu conteúdo varia de acordo com o interlocutor e com a destinação que é dada a esse relato.

Lahire (2004) fez coro às críticas de Bourdieu sobre o entendimento das histórias de vida como narrativas que privilegiavam a coerência de um percurso em detrimento das incertezas e contradições da vida real. Em sua concepção, o movimento de fazer deduções a partir da análise das práticas de um indivíduo, em certo contexto, e supor serem essas perfeitamente transferíveis a outros contextos, sem maiores reflexões, presente em parte dessas investigações, seria apressado. O autor considerava tal movimento como "preguiça empírica" e o colocava como uma "generalização abusiva" (LAHIRE, 2004, p. 9).

Nesse contexto de críticas à metodologia biográfica, e como um posicionamento crítico ao conceito de habitus de Bourdieu, que o Retrato Sociológico foi apresentado como um dispositivo teórico-metodológico inédito por Lahire (2002) em seu livro Portraits sociologiques: dispositions et variations individuelles. Lahire (2004) pretendia contribuir para um melhor entendimento da maneira pela qual a sociedade era refratada por um ator social, considerando ser possível captar, por meio desse dispositivo, a pluralidade das maneiras de ver, sentir ou agir (por ele conceituadas como disposições) em contextos diversos, presentes nas narrativas desse ator.

Para Lahire (2005), por meio desse dispositivo, seria possível questionar a apresentação de uma personalidade estável e coerente pelo investigado, omitindo as incertezas e indecisões que fazem parte da vida de todos os indivíduos, e assim, levando em conta tais incertezas e contradições, mas sem ceder à ilusão de que, ao fazer isso, seria possível apreender totalmente a personalidade de um indivíduo, Lahire compreendia ser factível renovar o gênero biográfico. 
Para tanto, Lahire (2004) apostou em uma pesquisa com caráter experimental, sem um tema ou objeto de pesquisa em suas concepções clássicas e que buscava "[...] testar empiricamente a validade e a pertinência relativas aos conceitos de disposição, competência, apetência, transferibilidade, ou de aplicar um dispositivo metodológico inédito para as necessidades dessa reflexividade" (LAHIRE, 2004, p. 20). Entendia que apenas quando são avaliados os conhecimentos criados a partir das mudanças na divisão dos objetos, na escala de observação ou no método de produção, e quando evita-se considerar esses novos conhecimentos construídos como a única verdade possível sobre o meio social, é que o caráter da metodologia poderia ser dito experimental, no sentido de novo, diferente do tradicional (LAHIRE, 2004). O ineditismo da metodologia também dizia respeito aos conhecimentos que proporcionava, visto que, na compreensão de Lahire (2005), apenas o Retrato Sociológico permitiria compreender questões referentes à ativação, inibição, suspenção, operacionalização e transferibilidade das disposições de um indivíduo.

Os Retratos Sociológicos apresentados em Portraits sociologiques: dispositions et variations individuelles foram construídos a partir de séries de seis entrevistas com temáticas diferentes: escola, trabalho, família, sociabilidade, lazer, práticas culturais e corpo - com oito investigados, sem que esses soubessem quais eram as hipóteses e as teorias que orientavam essa pesquisa. Apesar de possuírem temas definidos, uma das exigências teóricas de Lahire era de que a fala do entrevistado não fosse limitada quando esse se desviasse da temática inicial, pois, para ele, os universos de socialização são entrelaçados, e recorrentemente as respostas dos indivíduos às perguntas realizadas vinculam esses universos (LAHIRE, 2004).

O critério para escolha dos entrevistados foi a existência de certa relação de proximidade com os respectivos entrevistadores. Foram excluídas as pessoas muito próximas e as completamente desconhecidas. Assim, duas situações foram evitadas: uma mudança causada pelo processo investigativo no relacionamento interpessoal, caso os participantes fossem próximos, e a falta de confiança necessária para que o investigado pudesse se revelar, caso o investigador fosse um completo desconhecido. As entrevistas foram realizadas, em sua grande maioria, no domicílio dos entrevistados, com exceções feitas à ocorrida na casa de um dos entrevistadores e outras duas no ambiente de trabalho de um dos entrevistados (LAHIRE, 2004).

Segundo Lahire $(2004$, p. 33), “[...] em todos os casos, foram realizadas anotações etnográficas sobre a forma como o contato foi estabelecido, o local da entrevista e a maneira como se desenvolveram". Outros dados sobre os pesquisados foram levantados por meio de observações comportamentais realizadas pelo pesquisador em ambientes diversos, perguntas a terceiros (conhecidos dos investigados) ou a partir das produções intelectuais impressas desses sujeitos de pesquisa às quais o investigador teve acesso.

Após a transcrição das entrevistas, Lahire (2004, p. 45) organizou os relatos em uma narrativa, cujo título se restringia ao nome e sobrenome do entrevistado, para ressaltar o fato de que "[...] as diversas práticas, atitudes, etc. de um indivíduo singular não são redutíveis à uma fórmula geradora". Esses relatos, chamados por Lahire (2004) de estudos de caso, não apresentavam uma conclusão, em que as características dos entrevistados eram listadas coerentemente, mas traziam em seu final uma recapitulação dos pontos de análise, que exibiam indícios de quais 
disposições puderam ser inferidas e em que contextos elas eram ativadas ou inibidas. Apresentavam também considerações sobre a homogeneidade ou heterogeneidade desse grupo de disposições e se essas variavam de maneira diacrônica e sincrônica (LAHIRE, 2004).

\section{Como as teses revisadas foram selecionadas?}

Após essa descrição da metodologia criada por Lahire, apresentamos, nesta seção, os critérios utilizados para selecionar as teses que serão analisadas subsequentemente.

A fonte de dados utilizada nessa pesquisa foi o Catálogo de Teses \& Dissertações da Coordenação de Aperfeiçoamento de Pessoal de Nível Superior (CAPES), fundação vinculada ao Ministério da Educação, que tem como uma de suas missões a divulgação das produções acadêmicas, de pesquisa e educacionais brasileiras. Esse catálogo é, portanto, o repositório oficial do governo brasileiro e nos permitiu acesso a resumos de Dissertações e Teses defendidas de 1987 em diante (AZOUBEL, 2020).

Acessamos o sítio do referido catálogo (CAPES, 2021) na rede mundial de computadores e digitamos os termos 'Retratos' 'Sociológicos' 'Lahire', como se fossem uma expressão, no espaço de busca disponibilizado. Houve 2.137 resultados. Reduzimos esse número para 98 por meio das opções de refinamento: selecionamos o tipo Doutorado (teses), os anos 2011 a 2020, e as Áreas de Conhecimento Educação, Educação especial, Educação física, Ensino, Ensino de ciências e matemática e Ensino-aprendizagem.

Em seguida, tentamos acessar cada uma dessas 98 teses, seja por meio do endereço eletrônico presente na página de resultados do Catálogo de Teses \& Dissertações ou por meio de pesquisas nos motores de busca Google e Google Acadêmico. Não conseguimos encontrar, pelo método supracitado, três dessas produções acadêmicas. No caso de uma delas, inclusive, o resultado no catálogo apareceu duas vezes, o que reduziu nosso universo a 94 resultados.

As restantes foram acessadas e efetuamos uma busca pelo termo 'Lahire' no texto de cada uma delas, pois buscávamos as produções que utilizavam a metodologia criada por Bernard Lahire. Cinquenta e dois (52) arquivos não apresentavam esse termo no corpo do texto, e assim foram descartados. No caso das 42 teses restantes, efetuamos uma busca pelos termos 'Retratos' e 'Sociológicos', porque a obra de Lahire não se resume à elaboração desse dispositivo e descartamos aquelas em que os termos unidos 'Retratos' e 'Sociológicos': (a) não apareciam; (b) apareciam apenas no referencial teórico ou; (c) a metodologia utilizada na pesquisa apresentava aspectos que a diferenciava de maneira significativa do dispositivo elaborado por Lahire. Essas ações nos permitiram descartar mais 28 produções e chegar ao número final de 14 teses para a nossa revisão.

O resultado dessa revisão, analisando as aproximações e diferenças, tanto nos objetivos dessas pesquisas quanto nas metodologias utilizadas para a construção e para a análise dos dados e trazendo reflexões sobre as contribuições advindas do uso dos Retratos Sociológicos como instrumento teórico-metodológico para as conclusões presentes nas teses revisadas, será o tema da próxima sessão. 


\section{Como o Retrato Sociológico foi apropriado nas teses brasileiras publicadas entre os anos de 2011 e 2020?}

As 14 teses analisadas, com os seus respectivos anos de publicação, indicadores para referências futuras, títulos, nomes dos autores e áreas de conhecimento, são apresentadas no quadro abaixo:

Quadro 1 - Informações iniciais sobre as teses analisadas

\begin{tabular}{|c|c|c|c|c|}
\hline Ano & Indicador & Título & Autor & Área \\
\hline 2012 & I & $\begin{array}{l}\text { História e sociologia das práticas de leitura: A } \\
\text { trajetória de seis leitores oriundos do meio rural }\end{array}$ & Lisiane Sias Manke & Educação \\
\hline 2012 & II & $\begin{array}{l}\text { Letramentos de adultos em processo de } \\
\text { alfabetização: Reflexos da escolarização nas } \\
\text { práticas de leitura }\end{array}$ & Paula Alves de Aguiar & Educação \\
\hline 2013 & III & $\begin{array}{l}\text { Evasão do ensino superior de Física segundo } \\
\text { a tradição disposicionalista em sociologia da } \\
\text { educação. }\end{array}$ & $\begin{array}{l}\text { Paulo Roberto } \\
\text { Menezes Lima Junior }\end{array}$ & Ensino de Física \\
\hline 2013 & IV & $\begin{array}{l}\text { O que fizeram (e o que fizemos) de nós? Estudo } \\
\text { de caso das trajetórias escolares de alunos/ } \\
\text { as do ciclo básico de alfabetização (CBA) em } \\
\text { Minas Gerais }\end{array}$ & $\begin{array}{l}\text { Frederico Assis } \\
\text { Cardoso }\end{array}$ & Educação \\
\hline 2013 & v & $\begin{array}{l}\text { Relação aluno-instituição: O caso da licenciatura } \\
\text { do Instituto de Química da UNESP/Araraquara }\end{array}$ & Luciana Massi & Ensino de Química \\
\hline 2013 & $\mathrm{VI}$ & $\begin{array}{l}\text { Relações de estudantes de Letras com a leitura } \\
\text { literária: Entre leituras profissionais e comuns }\end{array}$ & $\begin{array}{l}\text { Maura Maria dos } \\
\text { Santos }\end{array}$ & Educação \\
\hline 2014 & VII & $\begin{array}{l}\text { As formas identitárias nos contextos de } \\
\text { trabalho: Uma análise da profissionalidade } \\
\text { docente }\end{array}$ & $\begin{array}{l}\text { Lúcia Matias da Silva } \\
\text { Oliveira }\end{array}$ & Educação \\
\hline 2014 & VIII & $\begin{array}{l}\text { Trajetórias educacionais de estudantes de curso } \\
\text { de Pós-Graduação da Unifran na modalidade } \\
\text { a distância }\end{array}$ & $\begin{array}{l}\text { Carmen Lúcia Tozzi } \\
\text { Mendonça Conti }\end{array}$ & Educação \\
\hline 2014 & IX & $\begin{array}{l}\text { Trajetórias em contraponto: Uma abordagem } \\
\text { microssociológica da formação superior em } \\
\text { piano em duas universidades brasileiras }\end{array}$ & Carla Silva Reis & Educação \\
\hline 2017 & $x$ & $\begin{array}{l}\text { A poesia em territórios improváveis: Jovens de } \\
\text { periferia em cena }\end{array}$ & $\begin{array}{l}\text { Helen Aparecida } \\
\text { Queiroz }\end{array}$ & Educação \\
\hline 2017 & $X I$ & $\begin{array}{l}\text { Afiliação institucional e intelectual de } \\
\text { estudantes cotistas de cursos de alta demanda } \\
\text { e seletividade social da Universidade Federal } \\
\text { de Santa Catarina }\end{array}$ & $\begin{array}{l}\text { Francini Scheid } \\
\text { Martins }\end{array}$ & Educação \\
\hline 2017 & XII & $\begin{array}{l}\text { Senso prático e reflexividade na prática de } \\
\text { quatro professores do Ensino Fundamental }\end{array}$ & Darbi Masson Suficier & Educação Escolar \\
\hline 2018 & XIII & $\begin{array}{l}\text { O bilinguismo português/polonês na } \\
\text { constituição disposicional e na prática: Perfis } \\
\text { sociológicos de cinco descendentes de } \\
\text { poloneses no município de Dom Feliciano/ RS }\end{array}$ & Rozele Borges Nunes & Educação \\
\hline 2019 & XIV & $\begin{array}{l}\text { Desenvolvimento profissional de professores } \\
\text { de Física: Um estudo sob a perspectiva } \\
\text { disposicionalista e contextualista da ação }\end{array}$ & $\begin{array}{l}\text { Wilson Elmer } \\
\text { Nascimento }\end{array}$ & $\begin{array}{l}\text { Ensino de Ciências e } \\
\text { Matemática }\end{array}$ \\
\hline
\end{tabular}

Fonte: elaborado pelos autores.

Das 14 teses revisadas, 11 estão listadas como pertencentes à Área de Educação e outras três como pertencentes à Área de Ensino. Baseados nesses números, podemos afirmar que a metodologia de Retratos Sociológicos é mais utilizada em investigações na Área de Educação do que na Área de Ensino. No entanto, destacamos o fato de que todas as teses na Área de Ensino podem ser classificadas como de Ensino de Ciências 
(Física; Química; Ciências e Matemática), o que reforça o entendimento de que existe potencial para que esse dispositivo seja utilizado em investigações especificamente nessa área.

Tal entendimento é dado a partir da compreensão de que, com um objetivo de pesquisa norteador, os resultados obtidos em investigações na Área de Ensino de Ciências que utilizaram os Retratos Sociológicos, construídos sobre um referencial teórico sociológico sólido e condensando dados e análise em um mesmo documento, são muito diferentes dos obtidos por meio de outras metodologias utilizadas nessa mesma área (LIMA JÚNIOR; MASSI, 2018, p. 50). Para estes autores, “[...] é justamente quando situamos o ensino de Ciências nos diversos contextos individuais que conseguimos encontrar respostas para algumas perguntas tipicamente feitas na pesquisa em educação científica".

Esse norte dado por um problema de investigação já nos permite estabelecer uma diferenciação entre a apropriação da metodologia realizada nas teses revisadas e a primeira vez que o Retrato Sociológico foi utilizado por Lahire (2004), em que não havia primordialmente um objeto de estudo clássico.

A leitura cuidadosa dos objetivos enunciados nas teses revisadas nos permite identificar pontos comuns de interesse, mesmo que existissem outros objetivos dissonantes e como esperado e desejado, os objetos de estudo de cada pesquisador fossem diferentes.

Um objetivo que perpassa todas as teses, seja ele enunciado como sendo o principal, como secundário ou como constituinte de uma análise multinível, é entender a trajetória escolar dos indivíduos investigados. O conceito de trajetória, definido como "[...] série de posições sucessivamente ocupadas por um mesmo agente (ou um mesmo grupo) num espaço que é ele próprio um devir, estando sujeito a incessantes transformações" (BOURDIEU, 1998, p. 189), é caro à teoria disposicionalista, pois situa os indivíduos em seu grupo social, com a construção diacrônica das trajetórias desses grupos delineadas claramente, evitando assim a construção narrativa realizada pelo investigado de uma história de vida coerente, ação essa criticada por Bourdieu em $A$ ilusão biográfica (MONTAGNER, 2007).

Outros objetivos enunciados nas teses revisadas que puderam ser agrupados por conta do interesse comum dos investigadores são:

a. compreender as possíveis relações causais entre os patrimônios de disposições dos investigados e suas práticas em diversos contextos sociais, como por exemplo, a prática de leitura (teses I, II, VI e X), a prática linguística (tese XIII) e a prática docente (teses VII, XII e XIV);

b. compreender a relação entre estudantes e instituições escolares (III, IV, V, VIII, IX e XI).

É possível relacionar esses interesses em comum presentes nas mencionadas investigações e os quatro grandes objetivos das investigações brasileiras na Área de Educação que se valem da metodologia biográfica (PASSEGGI; SOUSA, 2017):

1. compreender os processos de individuação e socialização dos indivíduos;

2. utilizar a metodologia para construir conhecimento sobre as práticas sociais do indivíduo e como esses lhes dão sentido;

3. utilizar o método biográfico como dispositivo de pesquisa-formação;

4. estudar a natureza e diversidade das biografias. 
Tal aproximação nos possibilita vislumbrar tanto o motivo que levou à escolha da metodologia dos Retratos Sociológicos pelos pesquisadores quanto as lacunas passíveis de serem preenchidas com o uso desse dispositivo dentro da investigação brasileira nas Áreas de Educação e Ensino.

Entendemos que os objetivos das pesquisas revisadas estão relacionados, principalmente, ao interesse em usar a metodologia biográfica como meio de construção de conhecimentos sobre as práticas sociais dos investigados e sobre a percepção dos sentidos atribuídos por esses investigados à essas práticas.

A possibilidade de estabelecer essa relação nos permite firmar a posição do Retrato Sociológico como um método investigativo biográfico válido e pertinente, passível de ser utilizado em pesquisas nas Áreas de Educação e Ensino, pois os objetivos das investigações revisadas coincidem com objetivos de outras metodologias biográficas.

O estabelecimento dessa relação ainda nos permite vislumbrar espaços inatingidos pelas teses revisadas e passíveis de serem desbravados em novas pesquisas. Vislumbramos a possibilidade, por exemplo, de realizar pesquisas cujo objetivo coincida com o terceiro grande objetivo listado por Passeggi e Souza (2017), ou seja, utilizar a construção de Retratos Sociológicos em pesquisas de formação de professores de diversas Áreas do Conhecimento, no sentido de formar os professores nesse processo de construção de seus Retratos Sociológicos.

Para iniciar a análise das metodologias utilizadas para a construção dos Retratos Sociológicos nas investigações revisadas, julgamos ser importante tabular algumas informações que nos permitam perceber as semelhanças e diferenças na apropriação do Retrato Sociológico pelos pesquisadores.

Quadro 2 - Informações metodológicas

\begin{tabular}{|c|c|c|c|c|}
\hline Indicador & $\begin{array}{l}\text { Principal método de coleta } \\
\text { de dados }\end{array}$ & $\begin{array}{l}\text { Número } \\
\text { de } \\
\text { retratados }\end{array}$ & $\begin{array}{l}\text { Número de entrevistas por } \\
\text { retratado }\end{array}$ & $\begin{array}{c}\text { Duração média de cada } \\
\text { entrevista }\end{array}$ \\
\hline 1 & Entrevistas em profundidade & 6 & No mínimo 4 e no máximo 6 & Entre 2 e 3 horas \\
\hline II & Entrevistas semidiretivas & 4 & $\begin{array}{l}5 \text { - *Exceção feita a um dos inves- } \\
\text { tigados, que desistiu do processo } \\
\text { após duas entrevistas. }\end{array}$ & Pelo menos $01 \mathrm{~h} 30$ \\
\hline III & Entrevistas em profundidade & 5 & 3 & Aproximadamente 2 horas \\
\hline IV & Entrevistas semiestruturadas & 8 & 1 & $01 \mathrm{~h} 30$ \\
\hline V & Entrevistas semiestruturadas & 27 & 1 & 2 horas \\
\hline VI & Entrevistas semidirigidas & 12 & $\begin{array}{l}1 \text { - *Exceção feita a uma das in- } \\
\text { vestigadas, que foi entrevistada } \\
\text { duas vezes. }\end{array}$ & Aproximadamente 1 hora \\
\hline VII & Entrevistas semiestruturadas & 3 & 4 a 7 & Não apresentou a informação \\
\hline VIII & Entrevistas semiestruturadas & 4 & 1 & Aproximadamente 2 horas \\
\hline IX & Entrevista semiestruturadas & 16 & 1 & Entre 40 minutos e 3 horas \\
\hline$X$ & Conversas em profundidade & 5 & $\begin{array}{l}1 \text { encontro individual e } 2 \text { encon- } \\
\text { tros coletivos }\end{array}$ & Não apresentou a informação \\
\hline $\mathrm{XI}$ & Entrevistas semiestruturadas & 8 & 1 & Não apresentou a informação \\
\hline XII & Entrevistas semiestruturadas & 4 & 2 & Entre $5 \mathrm{~h} 10$ e $7 \mathrm{~h} 15$ \\
\hline XIII & Entrevista em profundidade & 5 & Entre 2 e 4 & Entre $1 \mathrm{~h}$ e $3 \mathrm{~h} 30$ \\
\hline XIV & Entrevistas semiestruturadas & 4 & 3 & Não apresentou a informação \\
\hline
\end{tabular}

Fonte: elaborado pelos autores. 
É imprescindível iniciar a análise do quadro destacando que outros métodos de coleta de dados, como questionários socioeconômicos e observações etnográficas, para ficar em poucos exemplos, foram utilizados pelos pesquisadores de maneira complementar na construção dos Retratos Sociológicos presentes nas pesquisas revisadas, o que está de acordo com o modelo proposto por Lahire (2004).

Segundo nosso levantamento, o principal instrumento utilizado para essa construção foram as entrevistas semiestruturadas (semidiretivas, semidirigidas). Essa modalidade de entrevista é a que "[...] se desenrola a partir de um esquema básico, porém não aplicado rigidamente, permitindo que o entrevistador faça as necessárias adaptações" (LÜDKE; ANDRÉ, 1986, p. 34), o que possibilita a exploração dos saberes, crenças e valores dos entrevistados (LAVILLE; DIONNE, 1999). O uso desse tipo de entrevista está em consonância com a exigência teórica de Lahire (2004) de não estabelecer limites contextuais à fala do entrevistado, visto que existe o entrelaçamento dos universos de socialização dos indivíduos.

As entrevistas em profundidade, citadas pelas teses I, III e XIII, também podem ser caracterizadas como semiestruturadas, pois, a profundidade aqui está mais relacionada à densidade e extensão de cada entrevista. $O$ instrumento utilizado na tese $\mathrm{X}$, chamado de conversa em profundidade, difere dos demais por ser considerado como um tipo de entrevista não estruturada, que se aproxima de um diálogo natural entre dois indivíduos (QUEIROZ, 2017).

O número de retratados em cada pesquisa foi variado, e a seleção final ocorreu baseada na disponibilidade e no interesse desses indivíduos em participar de longas entrevistas (em metade das investigações, mais de uma). O início de cada um dos processos de seleção foi diverso, com pesquisadores partindo de respostas a questionários socioeconômicos fornecidos por instituições de Ensino Superior, de indicações realizadas por outrem e de fotos, para ficar em alguns exemplos.

Percebemos que poucas seleções (teses II, IV e XIII) respeitaram de algum modo o critério seletivo anunciado por Lahire (2004) de que deveria existir certa relação de proximidade entre investigadores e investigados. As entrevistas realizadas pelos pesquisadores nas teses revisadas foram, em sua maioria, com sujeitos desconhecidos, e isso pode ser compreendido pelo fato de que, muitas dessas pesquisas partiram com um norteador bem definido em meio a um universo amostral grande, até chegar a indivíduos disponíveis e dispostos em participar dessas investigações. Cabe também ressaltar que, assim como a maioria das entrevistas realizadas por Lahire (2004) e seus colaboradores, boa parte das entrevistas realizadas nas pesquisas revisadas ocorreu na casa dos investigados ou locais por eles escolhidos, para que esses se sentissem mais confortáveis para partilhar suas vivências nessas entrevistas de longa duração.

A maneira escolhida, pela maioria dos pesquisadores, para apresentar os dados obtidos em suas investigações foi similar ao modelo idealizado por Lahire (2004), pois os dados foram organizados em narrativas biográficas com excertos das falas transcritas dos investigados com análises e inferências do patrimônio de disposições realizadas pelo investigador permeando essas narrativas. Em algumas teses foram elaborados quadros de disposições e/ou notas sintéticas no final de cada Retrato para que alguns pontos de análise pudessem ser retomados ou explicitados. Julgamos serem essas características essenciais para que um trabalho de investigação possa ser 
caracterizado como sendo um Retrato Sociológico enquanto dispositivo que condensa dados e análise em um só documento (LIMA JÚNIOR; MASSI, 2018).

Por outro lado, a organização dos dados obtidos por meio das entrevistas em tabelas, sem uma narrativa biográfica e sem a inferência do patrimônio de disposições dos investigados, que pode ser percebida na tese VIII, nos leva a entender que a metodologia utilizada por esse pesquisador não pode ser caracterizada como Retrato Sociológico, pois não se assemelha ao modelo proposto por Lahire (2004) e nem aos demais métodos utilizados pelos pesquisadores que tiveram suas teses revisadas.

Constatamos que as teses restantes seguiram, em maior ou menor grau, o programa interpretativo concebido idealmente para os oito estudos de caso realizados por Lahire (2004), que tinha como base os seguintes aspectos: (1) reconstrução das disposições a partir da análise do material empírico; (2) constatação da variação ou não dos comportamentos conforme o contexto e a delimitação das áreas de atualização e de não atualização das disposições; (3) questionamentos sobre as propriedades sociais dos contextos em que as disposições sofrem atualizações ou não as sofrem; e (4) estabelecimento, quando possível, da gênese dessas disposições. (LAHIRE, 2004).

A ausência de inferências e discussões mais aprofundadas sobre o patrimônio de disposições dos investigados foi constatada em outros estudos revisados (II, X e XII). Compreendemos ser uma falha grave, pois o intuito de Lahire (2004) ao criar essa metodologia foi o de justamente esclarecer, com maior ou menor precisão, os seguintes pontos: (1) "[...] o grau de extensão e heterogeneidade dos universos, grupos ou indivíduos frequentados" (LAHIRE, 2004, p. 26) pelo sujeito de pesquisa; (2) as variações das disposições em suas dimensões diacrônica, durante a vida do sujeito, e sincrônica, em contextos diferentes no mesmo período; e por fim, (3) as crises ou tensões que poderiam revelar contradições ou defasagens entre as disposições do pesquisado (LAHIRE, 2004).

Ainda no campo das ressalvas, entendemos ser necessário um cuidado maior na inferência de certas disposições. É preciso saber distingui-las de paixões, por exemplo, que seriam disposições associadas a fortes apetências (LAHIRE, 2004). Afirmar que um indivíduo possui uma disposição para sem uma discussão aprofundada do que essa inferência significa e em que contextos ela pôde ser observada nos leva a questionar se o conceito de disposição, segundo o referencial teórico adotado, foi assimilado de maneira adequada pelos investigadores.

Em todo caso, as disposições reconstruídas ${ }^{1}$ pelos investigadores, analisadas sob as lentes dos referenciais teóricos mais pertinentes a cada investigação, foram utilizadas para construir conhecimentos sobre as trajetórias escolares, trajetórias profissionais e sobre as práticas dos indivíduos em contextos diversos, como as já citadas práticas de leitura, práticas linguísticas e práticas docentes.

Cabe destacar algumas investigações em que a análise do patrimônio disposicional dos investigados fez parte de uma análise sociológica mais ampla, composta por níveis analíticos diferentes, porém articulados. Na tese III, os Retratos Sociológicos foram construídos como parte do nível analítico individual, que foi articulado posteriormente aos níveis estrutural (análise baseada em informações educacionais e socioeconômicas) e institucional (análise baseada em dados obtidos por meio de um questionário). A tese $\mathrm{V}$ realizou análise institucional, utilizando 
como fonte de dados: (a) literatura sobre o assunto; (b) entrevistas já existentes de docentes e, (c) entrevistas com indivíduos vincula dos à instituição na época da pesquisa de documentos históricos. Foram considerados dados quantitativos - elementos socioeconômicos dos estudantes do instituto em análise - e dados qualitativos, dos quais os Retratos Sociológicos foram parte integrante.

Ao refletir sobre os avanços conquistados com a utilização do Retrato Sociológico como metodologia, Lahire (2004, p. 325) afirma que esse dispositivo permitiu perceber que as "[...] disposições são múltiplas, heterogêneas, de naturezas diversas e provêm frequentemente de aspectos ou de momentos muito diferentes da socialização", o que corrobora sua crítica ao mecanismo de simples transferência de disposições entre diferentes domínios da prática, enunciado por outros pesquisadores que se valiam da teoria disposicional para a compreensão de práticas dos indivíduos.

Essa reflexão mais ampla de Lahire é ratificada quando olhamos para as conclusões construídas nas teses revisadas. Para Nascimento (2019, p. 255), "[...] os esquemas de ação são incorporados pelos indivíduos nas variadas experiências sociais e passam a ser ativados ou enfraquecidos em situações ou contextos também variados", ou seja, não é possível afirmar existir a transferência inequívoca de uma disposição que se encontra ativa em um contexto para outro.

Outro fato que ratifica esse entendimento está relacionado à gênese das disposições. Nas investigações sobre as práticas de leitura, percebeu-se que a gênese da disposição para leitura (AGUIAR, 2012; MANKE, 2012; SANTOS, 2013) pôde ser atribuída às diversas experiências vivenciadas pelos indivíduos em seus variados contextos sociais.

Para Lima Júnior (2013, p. 197), esse tipo de análise permite “[...] estabelecer uma relação mais crítica sobre o que sugerem as estatísticas generalizantes", pois a generalização é facilmente desrespeitada quando se olha para o individual. Reis (2014, p. 193), no entanto, afirma que "[...] a despeito das singularidades de cada percurso, ao cotejar os retratos em uma análise transversal, foi possível identificar alguns determinantes sociais que parecem ter favorecido as tomadas de posição" por ela percebidas. Para Lahire (2004), o obstáculo não está na existência de determinantes sociais responsáveis por escolhas dos indivíduos, e sim no entendimento de que esses determinantes são os responsáveis por todas as escolhas realizadas por uma pessoa.

Oliveira (2014, p. 79) entende que a análise dos Retratos Sociológicos e das respostas ao questionário a permitiu concluir que as disposições construídas pelas docentes estão intrinsicamente ligadas às estruturas constituintes do habitus, "[...] sistema de disposições duráveis predispostas a funcionar como princípio gerador das práticas", de cada uma delas. Afirma também que os acionamentos dessas disposições nas respostas às demandas cotidianas no contexto de trabalho mostram a existência de uma tendência a manter uma regularidade orientada por esse habitus, o que permite concluir que esses acionamentos não chegam a promover a "reconfiguração identitária", mas evidenciam a existência de "formas identitárias" com rupturas e mudanças pautadas em fracas e provisórias mobilizações (OLIVEIRA, 2014, p. 203).

Já Massi (2013) aponta que, para além do uso dado ao seu objeto de estudo específico, a metodologia forneceu elementos passíveis de maior exploração em estudos sobre trajetórias na Educação Básica e Superior, como a "[...] heterogeneidade 
dos patrimônios familiares e o papel da Instituição na criação, ativação e desativação de disposições" (MASSI, 2013, p. 144).

No que diz respeito às vantagens de se utilizar o Retrato Sociológico como dispositivo investigativo em pesquisas na Área de Ensino, Nascimento (2019, p. 257) defende que

[...] o que aponta para essa perspectiva de análise um futuro promissor no campo das pesquisas em formação de professores, é o deslinde do papel das variações intraindividuais dos comportamentos, atitudes e práticas dos sujeitos, que abarca tanto uma dimensão diacrônica (disposições plurais incorporadas na trajetória de vida do professor) quanto uma sincrônica (contextos sociais nos quais o professor participa).

Lima Júnior (2013), traz outra contribuição potencial dos Retratos Sociológicos como metodologia de investigação na Área de Ensino, pois, quando o patrimônio de disposições individuais de estudantes é desvelado, torna-se possível

[...] orientar professores e gestores educacionais no que fazer sobre seus alunos que nunca são somente originados nesta ou naquela classe social, mas são mulheres, judeus, cristãos, escoteiros, militantes políticos, atletas, músicos e, em virtude de tudo isso, têm uma experiência social muito mais rica que qualquer esquema generalizante poderia supor. (LIMA JÚNIOR, 2013, p. 246).

Essa visão também é corroborada por outras investigações. Para Villani, Barolli e Nascimento (2020, p. 297), por exemplo, a reconstrução de trajetórias docentes “[...] trazem a possibilidade de se compreender os condicionantes que concorrem para que os professores possam tecer suas carreiras de maneira particular, oferecendo, assim, uma visão mais pormenorizada e orgânica sobre a formação de professores", o que pode ser considerado um avanço em relação à outras metodologias biográficas.

Consideramos pertinente reforçar a percepção de que as pesquisas aqui revisadas alcançaram tanto os objetivos propostos como também aventaram outras possibilidades de uso para os Retratos Sociológicos.

\section{Considerações finais}

A revisão de algumas das teses brasileiras publicadas entre 2011 e 2020, que utilizam o Retrato Sociológico como metodologia investigativa para a construção de conhecimentos nas Áreas de Educação e de Ensino, nos permitiu concluir que esse dispositivo, quando subordinado a um problema de pesquisa, contribui sobremaneira para a análise de como o social é apreendido pelos indivíduos.

Percebemos que essa subordinação a um problema de pesquisa, ao invés de descaracterizar o dispositivo proposto por Lahire (2004) - que, reforçamos, teve caráter experimental (no sentido de um teste), quando da sua proposição - possibilitou o seu uso em investigações de temáticas variadas. No caso de nosso recorte, as temáticas observadas foram relacionadas às trajetórias de escolarização, evasão no ensino superior, afiliação institucional, gosto pela leitura e reflexões sobre práticas docentes sob a lente da teoria disposicionalista. Ainda tratando das aproximações das metodologias utilizadas nas teses revisadas com o método elaborado por Lahire (2002), constatamos que, assim como nos Estudos de Caso apresentados no livro Portraits sociologiques: dispositions et variations individuelles, as entrevistas semidiretivas e 
quando possível, as observações etnográficas, foram as principais fontes de dados para a construção dos Retratos Sociológicos. Os patrimônios de disposições inferidos a partir das análises desses dados tiveram papel fundamental para que os pesquisadores pudessem estabelecer as relações necessárias para responder as questões levantadas em seus problemas de pesquisa.

Baseados na investigação que realizamos, afirmamos que esse potencial ainda é timidamente explorado, pois o número de teses que se enquadraram em nosso recorte, 14, é muito pequeno se comparado ao número de teses brasileiras nas Áreas de Educação e Ensino. Compreendemos, no entanto, que a diversidade de temas presentes em um número reduzido de teses é um bom indício do potencial de utilização dessa metodologia em investigações nessas áreas.

Destacamos também que o recorte utilizado aponta para um maior uso do Retrato Sociológico em pesquisas na Área de Educação, deixando claro que existe espaço para que esse método possa ser utilizado em pesquisas na Área de Ensino. Ainda mais inexplorada é a utilização dos Retratos Sociológicos em pesquisas nas quais os sujeitos investigados são professores, pois, apenas as teses VII, XII e XIV abordaram assuntos referentes à docência. Em nosso entender, isso é menos uma percepção de que o método seja inadequado para esse tipo de investigação e mais uma sinalização de que existe muito ainda a ser desbravado com a utilização dos Retratos Sociológicos em investigações na Área de Ensino, principalmente no que diz respeito às pesquisas sobre práticas docentes.

\section{Referências}

AGUIAR, P. A. Letramentos de adultos em processo de alfabetização: reflexos da escolarização nas práticas de leitura. 2012. Tese (Doutorado em Educação) - Centro de Ciências da Educação, Universidade Federal de Santa Catarina, Florianópolis, 2012.

AZOUBEL, M. S. Como planejar e executar buscas na literatura científica? Perspectivas em análise do Comportamento, São Paulo, v. 10, n. 2, p. 256-266, 2020. DOI: https://doi.org/gxxt.

BOURDIEU, P. A ilusão biográfica. In: FERREIRA, M. M.; AMADO, J. (org). Usos e abusos da história oral. Rio de Janeiro: Editora da FGV, 1998. p. 183-191.

CAPES. Catálogo de teses e dissertações. Disponível em: https://catalogodeteses.capes.gov.br/ catalogo-teses/\#!/. Acesso em: 14. jun. 2021.

CARDOSO, F. A. O que fizeram (e o que fizemos) de nós?: estudo de caso das trajetórias escolares de alunos/as do ciclo básico de alfabetização (CBA) em Minas Gerais. 2013. Tese (Doutorado em Educação) - Faculdade de Educação, Universidade Federal de Minas Gerais, Belo Horizonte, 2013.

CONTI, C. L. T. M. Trajetórias educacionais de estudantes de curso de pós-graduação da Unifran na modalidade a distância. 2014. Tese (Doutorado em Educação Escolar) - Faculdade de Ciências e Letras, Universidade Estadual Paulista, Araraquara, 2014.

LAHIRE, B. Patrimónios individuais de disposições: para uma sociologia à escala individual. Sociologia, Problemas e Práticas, Lisboa, n. 49, p. 11-42, 2005.

LAHIRE, B. Portraits sociologiques: dispositions et variations individuelles. Paris: Nathan, 2002.

LAHIRE, B. Retratos sociológicos: disposição e variações individuais. Porto Alegre: Artmed, 2004.

LAVILLE, C.; DIONNE, J. A construção do saber: manual de metodologia da pesquisa em ciências humanas. Porto alegre: Artmed, 1999. 
LIMA JÚNIOR, P. Evasão do ensino superior de física segundo a tradição disposicionalista em sociologia da educação. 2013. Tese (Doutorado em Ensino de Física) - Instituto de Física, Universidade Federal do Rio Grande do Sul, Porto Alegre, 2013.

LIMA JÚNIOR, P.; MASSI, L. Nossa lente e nossa técnica: fundamentos dos retratos sociológicos. In: MASSI, L.; LIMA JUNIOR, P.; BAROLLI, E (org.). Retratos da docência: contextos, saberes e trajetórias. Araraquara: Letraria, 2018. p. 20-51.

LIMA JÚNIOR, P.; MASSI, L. Retratos sociológicos: uma metodologia de investigação para a pesquisa em educação. Ciência \& Educação, Bauru, v. 21, n. 3, p. 559-574, 2015. DOI: https://doi. org/gxw5.

LÜDKE, M.; ANDRÉ, M. Pesquisa em educação: abordagens qualitativas I. São Paulo: EPU, 1986.

MANKE, L. S. História e sociologia das práticas de leitura: a trajetória de seis leitores oriundos do meio rural. 2012. Tese (Doutorado em Educação) - Faculdade de Educação, Universidade Federal de Pelotas, Pelotas, 2012.

MARTINS, F. S. Afiliação institucional e intelectual de estudantes cotistas de cursos de alta demanda e seletividade social da Universidade Federal de Santa Catarina. 2017. Tese (Doutorado em Educação) - Faculdade de Educação, Universidade Federal de Minas Gerais, Belo Horizonte, 2017.

MASSI, L. Relação aluno-instituição: o caso da licenciatura do Instituto de Química da UNESP/ Araraquara. 2013. Tese (Doutorado em Ensino de Ciências) - Instituto de Física e Faculdade de Educação, Universidade de São Paulo, São Paulo, 2013.

MASSI, L. Saberes docentes e disposições: aproximações possíveis. In: MASSI, L; LIMA JUNIOR, P; BAROLLI, E (org.). Retratos da docência: contextos, saberes e trajetórias. Araraquara: Letraria, 2018. p. 385-409.

MONTAGNER, M. Â. Trajetórias e biografias: notas para uma análise bourdieusiana. Sociologias, Porto Alegre, v. 9, n. 17, p. 240-264, 2007. DOI: https://doi.org/fh876f.

NASCIMENTO, W. E. Desenvolvimento profissional de professores de física: um estudo sob a perspectiva disposicionalista e contextualista da ação. 2019. 279 f. Tese (Doutorado em Ensino de Ciências e Matemática) - Instituto de Física, Universidade Estadual de Campinas, Campinas, 2019.

NUNES, R. B. O bilinguismo português/polonês na constituição disposicional e na prática: perfis sociológicos de cinco descendentes de poloneses no município de Dom Feliciano/ RS. 2018. Tese (Doutorado em Educação) - Faculdade de Educação, Universidade Federal de Pelotas, Pelotas, 2018.

OLIVEIRA, L. M. S. As formas identitárias nos contextos de trabalho: uma análise da profissionalidade docente. 2014. Tese (Doutorado em Educação) - Pontifícia Universidade Católica de São Paulo, São Paulo, 2014.

PASSEGGI, M. C.; SOUZA, E. C. O movimento (auto) biográfico no Brasil: esboço de suas configurações no campo educacional. Investigación Cualitativa, USA, v. 2, n. 1, p. 6-26, 2017.

PINEAU, G. As histórias de vida em formação: gênese de uma corrente de pesquisa-açãoformação existencial. Educação e Pesquisa, São Paulo, v. 32, n. 2, p. 329-343, 2006. DOI: https:// doi.org/d2rn3m.

QUEIROZ, H. A. A poesia em territórios improváveis: jovens de periferia em cena. 2017. 245 f. Tese (Doutorado em Educação) - Faculdade de Educação, Universidade Federal do Rio de Janeiro, Rio de Janeiro, 2017.

REIS, C. S. Trajetórias em contraponto: uma abordagem microssociológica da formação superior em piano em duas universidades brasileiras. 2014. Tese (Doutorado em Educação) - Faculdade de Educação, Universidade Federal de Minas Gerais, Belo Horizonte. 2014. 
SANTOS, M. M. Relações de estudantes de letras com a leitura literária: entre leituras profissionais e comuns. 2013. (Doutorado em Educação) - Faculdade de Educação, Universidade Federal de Minas Gerais, Belo Horizonte, 2013.

SUFICIER, D. M. Senso prático e reflexividade na prática de quatro professores do ensino fundamental. 2017. Tese (Doutorado em Educação Escolar) - Faculdade de Ciências e Letras, Universidade Estadual Paulista, Araraquara, 2017.

VILLANI, A.; BAROLLI, E.; NASCIMENTO, W. E. Revisitando trajetórias docentes: uma sinergia entre contextos e disposições. Investigações em Ensino de Ciências, Porto Alegre, v. 25, n. 3, p. 270-299, 2020. DOI: https://doi.org/gxxv. 